\title{
The importance of Yalu Jiang coastal wetland in the north Yellow Sea to Bar-tailed Godwits Limosa lapponica and Great Knots Calidris tenuirostris during northward migration
}

\author{
CHI-YEUNG CHOI, PHIL F. BATTLEY, MURRAY A. POTTER, KEN G. ROGERS \\ and ZHIJUN MA
}

\begin{abstract}
Summary
Bar-tailed Godwits Limosa lapponica and Great Knots Calidris tenuirostris are long-distance migratory shorebirds with declining numbers in the East Asian-Australasian Flyway. One of the most important staging sites for these two species during northward migration is Yalu Jiang coastal wetland in the north Yellow Sea. Historical counts have been limited to once a year and conducted at different periods; these yield inadequate data for population monitoring. We estimated the numbers of Bar-tailed Godwits and Great Knots and described their migration phenology during northward migration from 2010 to 2012 at the Yalu Jiang coastal wetland, using a combination of periodic area-wide counts over the migration period and a modelling approach that estimates passage times and total numbers of birds transiting. The mean arrival date for L. l. baueri godwits was 29 March and mean departure date was 8 May. Corresponding dates were 11 April and 15 May for L. l. menzbieri godwits and 7 April and 14 May for Great Knots. We estimated that an annual average of over 68,00o Bar-tailed Godwits and 44,00o Great Knots used the area on northward migration from 2010-2012. Our results indicate that the Yalu Jiang coastal wetland supports on average at least $42 \%$ of the flyway's northward-migrating L. l. baueri godwits, $19 \%$ of L. l. menzbieri godwits, and $22 \%$ of the Great Knots. Comparisons with historical counts conducted during peak migration periods indicate a 13\% decline in Bar-tailed Godwits since 2004 and an $18 \%$ decline in Great Knots since 1999. Our results confirm that the study area remains the most important northward migration staging site for Bar-tailed Godwits and indicate that it has become the most important northward migration staging site for Great Knots along the flyway.
\end{abstract}

\section{Introduction}

Shorebird populations along the East Asian-Australasian Flyway (hereafter EAAF) are among the most poorly known of the different flyways (Stroud et al. 2006). Many are declining, mainly due to wetland habitat loss through reclamation (Moores et al. 2008, Amano et al. 2010, Rogers et al. 2011) and Spartina invasion (Gan et al. 2009). Coastal wetlands in East Asia are particularly vulnerable due to dense human populations and rapid economic development in this region (Barter 2002). More than half of all Chinese coastal wetlands were lost between 1950 and 2000 (An et al. 2007) while $75 \%$ of the historical tidal flat area in the Republic of Korea was lost by 2010 (Moores 2012); rates of intertidal flat loss show no sign of slowing (MacKinnon et al. 2012, Murray et al. 2014). These coastal wetlands are important staging areas where shorebirds must stop and replenish their 
energy reserves so that they can complete their migrations (Choi et al. 2009, Warnock 2010, Battley et al. 2012, Hua et al. 2013, Ma et al. 2013). The loss of Saemangeum, in South Korea, led to significant local population declines in the 'Critically Endangered' Spoon-billed Sandpiper Eurynorhynchus pygmeus and the 'Vulnerable' Great Knot Calidris tenuirostris (Moores et al. 2008, Rogers et al. 2011). On a longer time-scale, little is known about trends in shorebird numbers at staging sites on the Chinese side of the Yellow Sea (but see Ma et al. 2009, Rogers et al. 2010, Yang et al. 2011).

The Chinese side of the Yalu Jiang coastal wetland (hereafter YLJ), located in the northern Yellow Sea (Figure I), is known to play an important role during northward migration for Bartailed Godwits Limosa lapponica and Great Knots, historically supporting more than 100,000 godwits and 55,000 knots (Barter et al. 2000, Riegen et al. 2014). Surveys on wintering grounds have shown declining trends for Bar-tailed Godwits in north-west Australia and in eastern Australia (Moreton Bay, Queensland) (Rogers et al. 2011, Wilson et al. 2011). Similar trends were recorded for wintering Great Knots in these two locations, as well as in Corner Inlet, Victoria (Rogers et al. 2011, Wilson et al. 2011, Minton et al. 2012). Meanwhile, numbers of Bar-tailed Godwits and Great Knots on migration at Saemangeum and adjacent estuaries declined by $11 \%$ and $80 \%$, respectively, from 2006 to 2008 (Moores 2012). There is an urgent need to quantify the current importance of YLJ to these two apparently declining species. Counts conducted at YLJ to date have been limited to once a year, often at different times of the migration period. These data are inadequate indicators of the true numbers of birds transiting the site and need reappraisal.

Bar-tailed Godwits are long-distance migrants, with two subspecies in the EAAF that are distinguishable morphologically in the field: L. l. baueri, which breeds in Alaska and spends the

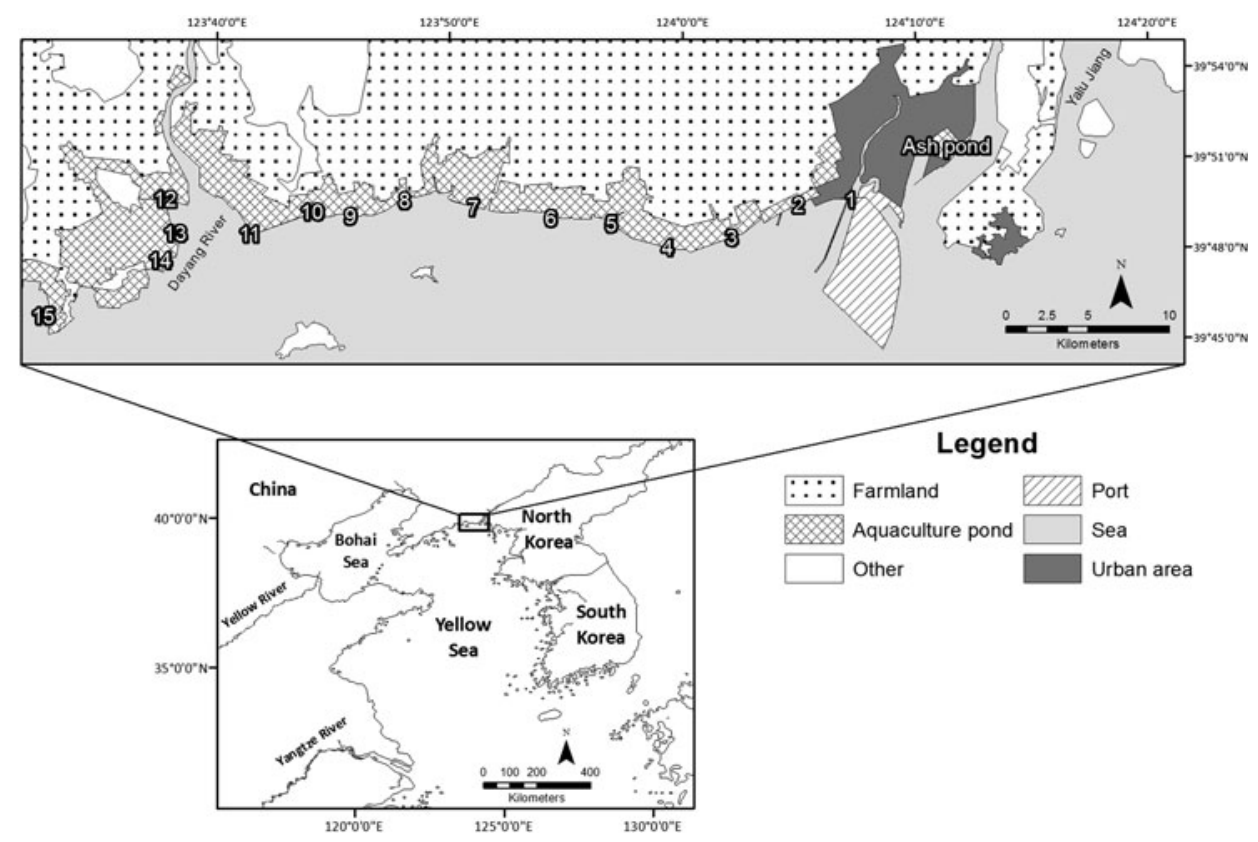

Figure 1. Map of Yalu Jiang coastal wetland, showing the 16 pre-roosts counted during censuses. The inset shows the location of Yalu Jiang coastal wetland within the Yellow Sea region. Note that the eastern and western boundaries of the Dandong Yalu Jiang Estuary Wetland National Nature Reserve were recently adjusted to exclude pre-roosts 1 and 15. The channel east of the Ashpond is the western branch of Yalu Jiang, which marks the boundary between China and North Korea. 
non-breeding season mostly in eastern Australia and New Zealand, and L. l. menzbieri, which breeds in north-east Siberia and spends the non-breeding season mainly in northern Australia (Engelmoer and Roselaar 1998, Wilson et al. 2007, Battley et al. 2012). An uncommon third, Russian-breeding, population has been suggested to warrant separate status (as L. l. anadyrensis) but is not considered further here as it is probably both rare and unable to be identified in the field (Engelmoer and Roselaar 1998, Tomkovich 2010). L. l. menzbieri and L. l. baueri are spatially segregated on their breeding areas and they seldom mix in their wintering ranges (Engelmoer and Roselaar 1998, Wilson et al. 2007). However, they do overlap spatially and temporally during northward migration in the Yellow Sea region, although L. l. menzbieri seems to predominantly use the western Yellow Sea and L. l. baueri mainly the eastern Yellow Sea (Battley et al. 2012). YLJ seems to be at the junction of the ranges of these two subspecies on northward migration. It is estimated that 133,000 L. l. baueri and 146,000 L. l. menzbieri occur in the EAAF (Wetlands International 2013). The Great Knot is endemic to the EAAF; it breeds in north-east Siberia and spends the non-breeding season mainly in Australia and south-east Asia (Piersma et al. 1996). The distributions of Great Knots during the breeding and non-breeding seasons are similar to those of L. l. menzbieri, but Great Knots mainly use the eastern Yellow Sea for staging, with large numbers historically known at Saemangeum (Moores 2012) and YLJ (Riegen et al. 2014).

Shorebird populations in China are usually monitored through monthly synchronised censuses (China Coastal Waterbird Census Group 2009, 2011), with peak counts from these censuses during migration periods often being treated as the total number of birds transiting the area. Such an approach is applicable at non-breeding sites, but not at staging or stopover sites, where some individuals of a species may depart before all have arrived. In this circumstance, the maximum count underestimates the total number of birds passing through the site (Thompson 1993, Ma et al. 2013). Recent attempts to overcome this problem took detection probability, sampled proportion of study area, length of stay, or residence probability into account when estimating the number of birds transiting (Farmer and Durbian 2006, Cohen et al. 2009). However, a reliable estimate of the length of stay or residence probability often requires radio tracking, unbiased capture-recapture, or resightings of individual birds (Frederiksen et al. 2001, Farmer and Durbian 2006, Cohen et al. 2009, Matechou et al. 2013), and these are not easy to achieve or to apply on large scales for conservation purposes. Some of these modelling estimates tend to be less reliable with small sample sizes (Frederiksen et al. 2001) and the ways to estimate stopover duration remain debatable (Efford 2005, Pradel et al. 2005).

Here we describe the migration phenology and estimate the numbers of Bar-tailed Godwits and Great Knots on northward migration at YLJ, using count data collected across three consecutive years (2010-2012). To overcome the analytical issues mentioned above, we modelled numbers of birds and passage times using repeated within-season counts, following the approach of Thompson (1993) as developed in Rogers et al. (2010). We also discriminated between the two godwit subspecies by estimating subspecies proportions from photographs of flying flocks across the migration period. We evaluate the effectiveness of different counting approaches (periodic synchronised censuses and regular partial counts) as well as the accuracy of the models, by comparing the passage times obtained from model estimates to those from remote-tracking studies. Sightings of colour-banded individuals were used to provide an independent estimate of the proportion of the flyway population of these two species staging at YLJ.

\section{Methods}

\section{Study area}

This study was carried out in the Dandong Yalu Jiang Estuary Wetland National Nature Reserve $\left(39^{\circ} 40^{\prime}-39^{\circ} 58^{\prime} \mathrm{N}, 123^{\circ} 34^{\prime}-124^{\circ} \mathrm{O} 7^{\prime} \mathrm{E}\right.$, Figure I) and its surrounding area. The study area has been historically referred as Yalu Jiang National Nature Reserve (Barter 2002, Bamford et al. 2008), Yalujiang River Estuary Wetland Nature Reserve (UNDP/GEF 2007), Yalu Jiang Estuary (BirdLife 
International 2009), Yalu River Estuary Nature Reserve (Li et al. 2009), and Yalu Estuarine Wetland Nature Reserve (Ma et al. 2013). However, there is another reserve, the Yalu Jiang Shangyou National Nature Reserve, located at the upper reaches of the river. For simplicity and clarity, we have used Yalu Jiang coastal wetland to describe the study area. The reserve within the study area was founded in 1987 and listed as a National Nature Reserve in 1997 (Yan 2008). It is located west of the Yalu Jiang estuary in the northern part of the Yellow Sea, near the border of China and North Korea (Figure 1). The reserve extends for about $70 \mathrm{~km}$ along the coast, with a total area of 101,000 ha, within which 14,082 ha is assigned as the core area (Yan 2008). The coastal area of the reserve is composed mainly of bare intertidal mudflat and sometimes Phragmites-dominated saltmarsh on the seaward side of the seawall, with aquaculture ponds and paddy fields on the landward side, a typical coastal landscape of the Chinese coast (Choi et al. 2014). Aquaculture ponds are used to cultivate sea cucumber, jellyfish, shellfish, prawn and fish while the bare intertidal mudflat is also used for shellfish farming. More than 250 species of birds have been recorded, with at least 29 species listed as 'Threatened' on the IUCN Red List (Yan 2008, IUCN 2012). The reserve was believed to support more than 200,000 shorebirds during the northward migration (Barter et al. 2000). The reserve is regarded as an Important Bird Area (BirdLife International 2009) but lacks Ramsar recognition (Ramsar 2012).

\section{Bird counts}

Tides at YLJ are semi-diurnal, with spring high tides inundating most, if not all, of the intertidal flats. As the tide approaches the seawall, birds are forced to concentrate at pre-roosts - upper intertidal flats that are last covered by tide - before flying towards aquaculture or abandoned ponds on the landward side of the seawall to roost (Barter and Riegen 2004). We adopted Barter and Riegen's (2004) approach and conducted counts among 15 identified fixed pre-roosts because the birds were often concentrated at these roosts. Counts from an additional roost (Ashpond; Figure 1) $7 \mathrm{~km}$ further east of the reserve's eastern boundary were also included as significant numbers of birds were recorded there (Riegen et al. 2014).

High tide counts of all shorebird species were conducted between March and May in 20102012, with priority given to Bar-tailed Godwit and Great Knot counts. Regular partial counts were conducted only on the eastern half of the reserve where more than $70 \%$ of our target species were recorded (Riegen et al. 2014). Pre-roosts 2, 5 and 6 were chosen as the main counting locations because the 'catchments' for these locations were less likely to overlap with nearby pre-roosts. Counts were conducted daily in at least one of these pre-roosts in 2011, yielding the most comprehensive counting effort; the next most frequent counts were in 2010. YLJ-wide periodic synchronised censuses were conducted four to five times each year at high tide during spring tide, covering up to 12 pre-roosts (average $=7$ ) and were completed within an average of three days. Most of the counts were conducted on incoming tides (243 cases) while a few were conducted during falling tides ( 17 cases). The latter may under-count the total number of birds because some individuals may not return until the tide dropped too far from the seawall for accurate counting. Therefore, we counted birds during falling tides only at locations with lower numbers of birds to minimise biases. Sightings of colour-banded individual Bar-tailed Godwits and Great Knots during fieldwork were also recorded to provide an independent measure of the proportion of the flyway migrant population of these two species staging at YLJ.

\section{Data analysis}

\section{Subspecies analysis}

In 2010 and 2011, photos of Bar-tailed Godwits in flight were taken in the field and used to estimate the proportions of L. l. baueri and L. l. menzbieri over the migration period. The two subspecies are differentiated by the whitish rump and lower back in L. l. menzbieri and darker 
rump and lower back in L. l. baueri (Engelmoer and Roselaar 1998, Wilson et al. 2007, Tomkovich 2010). For dates when more than one clear photo was available, numbers of each subspecies were summed, using photos considered most likely to be independent. Double-counting was possible, but given the small proportion of birds counted in photos compared to those counted in the field each day (mode $0.4 \%$ and median of $2.2 \%$ ), the likelihood of double-counting was negligible. The overall patterns of subspecies' proportions were similar in 2010 and 2011. Therefore, data were combined for analysis using weighted averages if photos were available for the same date in both years (Table $S_{I}$ in the online Supplementary Materials). Daily subspecies proportions of $L . l$. baueri were smoothed (SYSTAT 12, Systat Software Inc 2007: NONLIN Smooth and Plot Feature with polynomial smoothing, Gaussian kernel, nearest neighbour proportion $=0.25$ ) with two outliers excluded (the largest positive and negative residuals that affect the overall shape of the curve). The resulting smoothed subspecies proportions were used in analyses. Our assumption that the passage times between 2010 and 2012 are the same should be reasonable as L. l. baueri has been found to have consistent migration timing between years (Battley 2006, Conklin and Battley 2011, Conklin et al. 2013). The numbers of L. l. baueri and L. l. menzbieri at each pre-roost were calculated as the product of the number of Bar-tailed Godwits counted in the field and the proportion of each subspecies estimated by the smoothing method described above. No adjustment was required for Great Knots which are monotypic.

\section{Parameter estimation}

Thompson (1993) described a model of migrants transiting a staging site which estimates the number of birds present on any day based on the size of the transiting population and the difference between the proportion of transiting population which has arrived by that day and the proportion which has departed. Given enough daily counts over the staging period and assuming normally distributed arrival and departure times, the size of the transiting population and the parameters of the arrival and departure time distributions can be estimated. Our situation is more complex than that described by Thompson (1993) in that we have three years of data. Preliminary modelling (and experience elsewhere such as Riegen et al. 2014) indicated that whilst the numbers of birds transiting varied from year to year, arrivals and departures followed the same timing pattern in each year. Assuming the same species-specific passage times in each year for both species, we calibrated the following model:

$$
\text { Count }_{j, d a y}=\sum_{j=1}^{3}\left(a_{j} n_{j}\right) *\left(Z C F\left(\text { day }_{,} m 1, s 1\right)-Z C F(\text { day }, m 2, s 2)\right)
$$

Where $j$ is the year index: 1 for 2010, 2 for 2011,3 for 2012,

Count $_{j, \text { day }}$ is the observed number of birds present on the indicated day in year $j$,

$a_{j}$ is a dummy variable set to 1 for observations in year $j$, and o otherwise,

$n_{j}$ is the estimated size of the transiting population in year $j$,

$m 1, s 1$ are the estimated mean and standard deviation of arrival dates,

$m 2, s 2$ are the estimated mean and standard deviation of departure dates,

$Z C F($ day, $m, s)$ is the cumulative normal distribution for a mean of $m$ and a standard deviation of $s$.

Stopover duration was calculated as the difference between the estimated arrival and departure dates. The variance of stopover duration was calculated using Systat outputs as Variance(arrival) + Variance(departure) + 2 x Covariance (arrival, departure).

Calibration of this model followed Rogers et al. (2010) using the non-linear modelling procedure in SYSTAT 12 (Systat Software Inc 2007) with a least-squares loss function. Starting values 
of the parameters to be estimated are needed for the calibrations. We estimated starting values based on the number of birds counted during peak counts and tracking results from previous studies. Estimates from non-linear models may be sensitive to small differences in the initial estimates and different starting values may yield different parameter estimates. We used a range of starting values to check that our estimates were robust.

Estimates of passage times and total number of birds through modelling were based on two different, but non-exclusive datasets to evaluate the effectiveness of different counting approaches. The first dataset "Periodic synchronised censuses" included data from broad scale censuses of the entire study area. These censuses were conducted $4-5$ times per season but covered a larger area than the other dataset over the three years. Counts from different pre-roosts were summed for each survey except records where double counting was suspected. Two counts that only involved pre-roosts 2 and 6 before the arrival of birds in the early season were added to the dataset for 2011 and 2012 to improve the estimate of arrival time.

The second dataset "Regular partial counts" included data from selected pre-roosts (2,5 and 6), which were counted frequently over the three years. The size of the area to be counted precluded a complete count of these three pre-roosts within one day. Accordingly, counts were made at different pre-roosts and summed for analysis in a 4-day block. For pre-roosts where more than one count was carried out within a 4 -day block, the average was used. The core roosting site, pre-roost 2 , typically held a disproportionate number of birds ( $42 \%$ of Bar-tailed Godwits and $25 \%$ of Great Knots, A. Riegen unpubl. data), and therefore we ensured in the analysis that the 4-day block always included one count from pre-roost 2 . These yielded thirty-seven 4-day blocks and thirtyfive 4-day blocks for Bar-tailed Godwits and Great Knots, respectively, over three years of study. More than half of these blocks consisted of counts from all three pre-roosts while most of the remaining consisted of two pre-roosts.

Both datasets provided estimates of passage times but only the periodic synchronised censuses (which covered the whole reserve) could yield an estimate of total number of birds at YLJ. Therefore, total numbers at YLJ were modelled from the synchronised censuses using ( $I$ ) passage times and standard deviations generated directly from that dataset, and (2) passage times and standard deviations generated from the partial counts data set. The accuracy of estimates using these two approaches was evaluated by comparing their estimated passage times with available data from satellite tracking, radio tracking and geolocator studies on the same populations. This was achieved by obtaining the z-value (Zar 1999) and using a significance level ( $\alpha$ ) of 0.05 (arrival dates in Great Knots were not compared due to uncertainty in the accuracy of arrival dates based on radio tracking).

\section{Importance of Yalu Jiang coastal wetland}

The true number of migrants presumably varies between years according to differences in breeding success and mortality in previous years. To accommodate this concern in our estimates of the proportion of the flyway populations that occurred at YLJ, we used the non-breeding data (Bamford et al. 2008, Li et al. 2009) to give estimates of the proportions of the total non-breeding populations of the two godwit subspecies and Great Knots that occur in north-west Australia (Eighty Mile Beach and Roebuck Bay) and New Zealand. We then used recent survey data from north-west Australia (C. Hassell, D. Rogers and the Australasian Wader Studies Group unpubl. data) and New Zealand (A. Riegen and the Ornithological Society of New Zealand unpubl. data) to estimate the size of the latest populations in these non-breeding grounds from 2010 to 2012. These latest population estimates in the survey regions were then divided by the proportions calculated above to give estimates of the the total flyway populations in the years of our study. As most immature birds of both study species do not migrate north, we used survey data from the non-breeding and breeding periods to estimate the proportions of non-migrating and migrating birds over the study period, and applied these to the adjusted flyway estimates (Table 1 ). These processes yielded only a rough estimate of the size of the total flyway population due to limited 
Table 1. Estimated numbers of northward-migrating Bar-tailed Godwits and Great Knots 2010-2012 along the East Asian-Australasian Flyway (EAAF), based on published literature and recent non-breeding count data in north-west Australia (Eighty Mile Beach, Roebuck Bay) (C. J. Hassell, D. I. Rogers, and the Australasian Wader Studies Group unpubl. data) and New Zealand (A. C. Riegen and the Ornithological Society of New Zealand unpubl. data).

\begin{tabular}{|c|c|c|c|c|c|c|c|}
\hline Species & Location & Period & $\begin{array}{l}\text { Proportion } \\
\text { of EAAF } \\
\text { population }\end{array}$ & $\begin{array}{l}\text { Non- } \\
\text { breeding } \\
\text { population }\end{array}$ & $\begin{array}{l}\text { Projected } \\
\text { EAAF } \\
\text { population }\end{array}$ & $\begin{array}{l}\text { Migrant } \\
\text { proportion } \\
\text { in March }\end{array}$ & $\begin{array}{l}\text { Number of } \\
\text { migrants }\end{array}$ \\
\hline \multirow{3}{*}{$\begin{array}{l}\text { L. l. baueri } \\
\text { godwit }\end{array}$} & \multirow[t]{3}{*}{ New Zealand } & $2009-10$ & \multirow[t]{3}{*}{$0.67^{A}$} & 87,590 & 130,457 & 0.86 & 111,748 \\
\hline & & $2010-11$ & & 101,459 & 151,114 & 0.91 & 137,485 \\
\hline & & $2011-12$ & & 88,949 & 132,482 & 0.84 & 111,511 \\
\hline \multirow{3}{*}{$\begin{array}{l}\text { L. l. menzbieri } \\
\text { godwit }\end{array}$} & \multirow[t]{3}{*}{ NW Australia } & 2009-10 & \multirow[t]{3}{*}{$0.70^{\mathrm{B}}$} & 70,056 & 100,233 & 0.88 & 87,997 \\
\hline & & $2010-11$ & & 81,229 & 116,219 & 0.89 & 103,781 \\
\hline & & $2011-12$ & & 86,498 & 123,758 & 0.84 & 104,405 \\
\hline \multirow[t]{3}{*}{ Great Knot } & \multirow[t]{3}{*}{ NW Australia } & $2009-10$ & \multirow[t]{3}{*}{$0.48^{\mathrm{C}}$} & 92,801 & 195,174 & 0.87 & 169,998 \\
\hline & & $2010-11$ & & 121,860 & 256,289 & 0.96 & 245,933 \\
\hline & & $2011-12$ & & 122,065 & 256,720 & 0.84 & 214,572 \\
\hline
\end{tabular}

AProportion of New Zealand Bar-tailed Godwits to the EAAF population based on Bamford et al. 2008 $(104,068) / 155,000$.

BProportion of north-west Australia Bar-tailed Godwits to the EAAF population based on Li et al. 2009 $(25,000+93,818) / 170,000$.

CProportion of north-west Australia Great Knots to the EAAF population based on Bamford et al. 2008 $(158,082+22,600) / 380,000$.

study sites and old datasets, thus the results should not be treated as a reappraisal of flyway estimates. Nonetheless, this is the best possible approach we have in order to estimate the proportion of flyway populations that occurred at YLJ.

The frequency of resighting colour-banded birds also provides evidence for the importance of YLJ. Not all colour-marked birds present could be seen due to the large area of the study sites and large numbers of birds present. The number of colour-banded birds overlooked was estimated by assuming a quadratic relationship between the number of colour-banded birds and the frequency with which such birds were recorded. This approach provided a better fit of the model to the data than other possible relationships (e.g. exponential relationship in Rogers et al. 2010) and yielded an estimate of the total number of colour-banded birds in the study area. In combination with the numbers banded in north-west Australia and New Zealand, and assuming a survival rate of $90 \%$ for L. l. baueri (P. F. Battley unpubl. data), 81\% for L. l. menzbieri and $82 \%$ for Great Knots (Milton et al. 2005), we calculated the proportions of birds from these non-breeding grounds estimated to have used YLJ during northward migration during the study period.

\section{Results}

Regular counts at pre-roosts 2, 5 and 6 recorded the first Bar-tailed Godwit on II March 2011, and around 150 were still present at the end of May 2011. The first Great Knot was recorded on 18 March in both 2010 and 2011 with about 200 remaining at the end of May 2010. Photographic assessment of godwit subspecies from 99 of 162 field days in 2010 and 2011 indicated that L. l. baueri dominated at YLJ from the beginning of the migratory season in the middle of March until early May (Figure 2, Table SI). The relative proportion between the two subspecies stabilized at 0.7 L. l. baueri between mid-April and early May before steadily reducing. Similar patterns in the relative proportion of L. l. baueri were found in both 2010 and 2011, therefore smoothed results from combining these two years' data were used for further analysis.

The estimates of passage times from modelling of the two datasets yielded different results (Table 2). There were no significant differences in the arrival dates, departure dates or stopover 


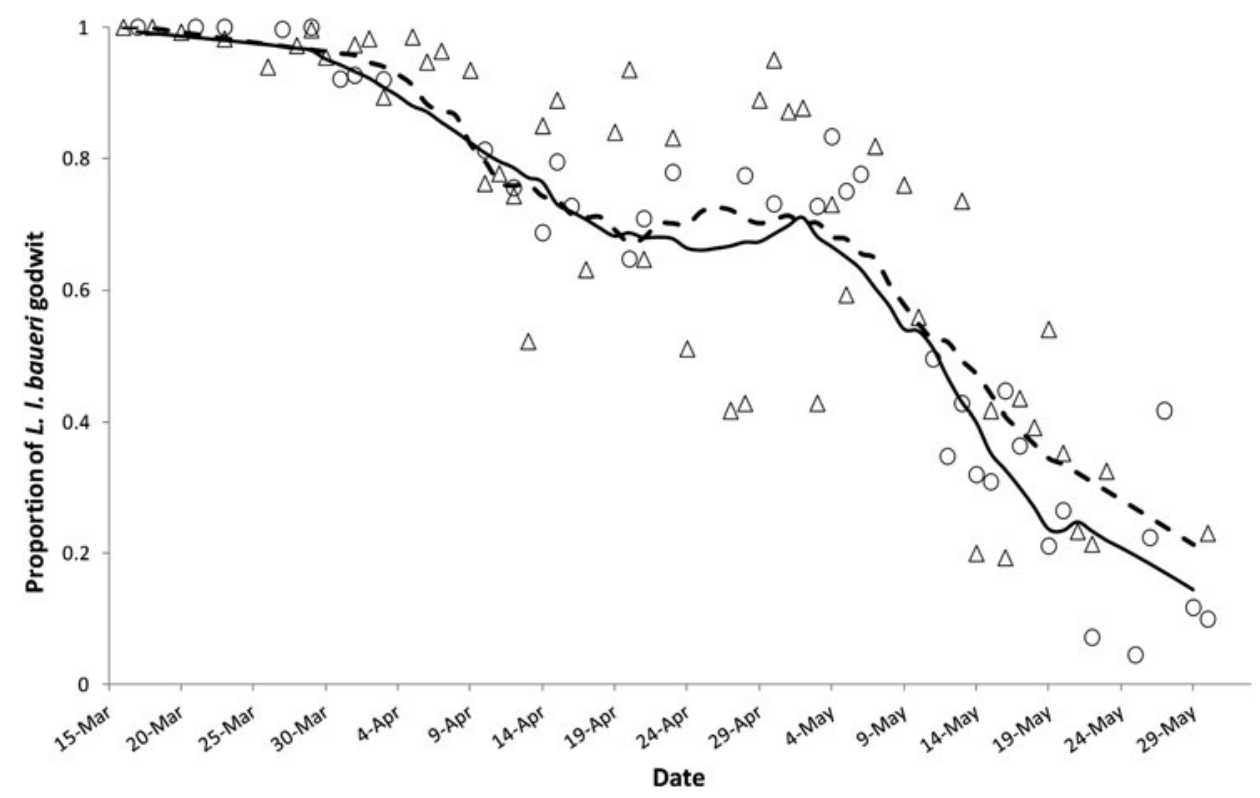

Figure 2. The change in proportion of L. l. baueri and L. l. menzbieri godwits over time at the Chinese side of Yalu Jiang coastal wetland during northward migration in 2010 and 2011. Open circles and open triangles denote the proportion of L. l. baueri obtained from photos taken in the field in 2010 and 2011, respectively. The solid line and dashed line denote the smoothed proportion of L. l. baueri in 2010 and 2011, respectively.

durations between the periodic synchronised census datasets and tracking studies $(P>0.05)$ for all three populations. In contrast, the regular partial count dataset yielded substantially earlier departure (26 days earlier, $P=0.11$ ) and shorter stopover duration ( 16 days shorter, $P=0.12$ ) than the tracking data for L. l. menzbieri (Table 2). The estimated mean departure date from the regular partial count dataset was even earlier than the earliest departure date recorded from tracking studies. Therefore, the periodic synchronised census dataset yielded more reasonable passage time estimates than the regular partial counts dataset did. Nevertheless, we present population estimates derived from the use of both sets of passage time estimates for comparison. Adjusting the starting values resulted in only very minor changes to parameter estimates, indicating that our estimates were reasonably robust (Table $\mathrm{S}_{2}$ ).

Modelling results based on the periodic synchronised census dataset (counts plus derived passage times) indicated that L. l. baueri arrived and departed earlier than L. l. menzbieri and Great Knots, although the differences were not statistically significant between species $(P>0.05)$ (Figure 3, Table 2). Small numbers of L. l. baueri evidently departed YLJ before all L. l. baueri had arrived, while there was no overlap in arrival and departure days in L. l. menzbieri and Great Knots (Figure 3). L. l. baueri staged at YLJ for 40 days while L. l. menzbieri and Great Knots staged for 34 days and 38 days respectively (Table 2). Total population estimates (based on the periodic synchronised census dataset) showed a significantly higher estimate in 2010 than the other two years for both L. l. baueri and Great Knots $(P<0.05$, except L. l. baueri between 2010 and 2011 where $P=0.07$ ) (Table 3 ). On average, YLJ supported more than 68,ooo Bar-tailed Godwits and 44,000 Great Knots during northward migration from 2011 to 2012 (Table 4).

Based on the modelled estimates at YLJ and the estimate of flyway populations using counts from non-breeding grounds, YLJ supported an average of at least $42 \%$ of northward-migrating L. l. baueri, $19 \%$ of L. l. menzbieri, and $22 \%$ of Great Knot along the EAAF (Table 4). 
Table 2. Estimated arrival dates, departure dates and stopover durations of Bar-tailed Godwits and Great Knots at Yalu Jiang coastal wetland (China) during northward migration, derived from counts (periodic synchronised censuses and regular partial counts) and from remote tracking data (satellite tracking, radio tracking and geolocator studies).

\begin{tabular}{|c|c|c|c|c|c|c|c|}
\hline $\begin{array}{l}\text { Species/ } \\
\text { Subspecies }\end{array}$ & Dataset & $\begin{array}{l}\text { Mean } \\
\text { arrival date }\end{array}$ & SD & $\begin{array}{l}\text { Mean } \\
\text { departure } \\
\text { date }\end{array}$ & SD & $\begin{array}{l}\text { Stopover } \\
\text { duration }\end{array}$ & SD \\
\hline \multirow{3}{*}{$\begin{array}{l}\text { L. l. baueri } \\
\text { godwit }\end{array}$} & Synchronised censuses & 29-Mar & 10.5 & 8-May & 6.2 & 39.7 & 2.9 \\
\hline & Partial counts & 26-Mar & 6.2 & 27-Apr & 11.1 & 31.8 & 2.0 \\
\hline & $\begin{array}{l}\text { Tracking records } \\
\qquad\left(n=20,19^{\mathrm{A}}\right)\end{array}$ & 30-Mar & 6.2 & 6-May & 5.6 & $37 \cdot 0$ & $5 \cdot 9$ \\
\hline \multirow{3}{*}{$\begin{array}{l}\text { L. l. menzbieri } \\
\text { godwit }\end{array}$} & Synchronised censuses & I1-Apr & $5 \cdot 4$ & 15-May & 0.1 & 34.1 & 2.5 \\
\hline & Partial counts & 8-Apr & 6.7 & $25-A p r$ & 15.1 & 16.3 & 8.0 \\
\hline & $\begin{array}{l}\text { Tracking records } \\
\qquad\left(n=3^{\mathrm{A}}\right)\end{array}$ & 18-Apr & 5.1 & 20-May & 3.2 & 32.0 & 6.2 \\
\hline \multirow[t]{3}{*}{ Great Knot } & Synchronised censuses & 7-Apr & 3.2 & I4-May & 0.6 & 37.5 & 0.8 \\
\hline & Partial counts & 6-Apr & 2.9 & 17-May & 2.8 & 41.1 & 2.8 \\
\hline & $\begin{array}{l}\text { Tracking records } \\
\qquad\left(\mathrm{n}=24,6^{\mathrm{B}}\right)\end{array}$ & NA & & 13-May & 11.1 & $40.8^{C}$ & 12.0 \\
\hline
\end{tabular}

A Data obtained from satellite tracking (P. F. Battley unpubl. data) and geolocator studies (J. R. Conklin unpubl. data), $n=20$ for arrival date, $n=19$ for departure and stopover duration.

${ }^{B}$ Data obtained from radio tracking (Z. J. Ma unpubl. data); $n=24$ for departure, $n=6$ for stopover duration.

CBased on individuals that arrived before $10^{\text {th }}$ April and departed after April, but likely to be an underestimate as it involved four birds radio-tagged locally when the arrival dates were not known.

Resighting data suggested that an average of $52 \%$ of New Zealand colour-banded L. l. baueri, 10\% of north-west Australia colour-banded L. l. menzbieri and 29\% of north-west Australia colourbanded Great Knots staged at YLJ during northward migration between 2010 and 2012 (Table 4).

\section{Discussion}

\section{Estimation of migrant population sizes and migration phenology}

Our modelling results confirm that YLJ is an important staging site for Bar-tailed Godwits and Great Knots, with an annual average of 68,0oo Bar-tailed Godwits and 44,0oo Great Knots using the area during northward migration over the period 2010-2012. The Bar-tailed Godwit population at YLJ is dominated by L. l. baueri, which comprises around $70 \%$ of the total godwit population. An average of at least 49,000 L. l. baueri and 18,000 L. l. menzbieri staged at YLJ during the study period. This is consistent with satellite tracking data and resightings of individually-marked birds that showed a more easterly distribution for L. l. baueri than L. l. menzbieri within the Yellow Sea (Barter and Riegen 2004, Wilson et al. 2007, Battley et al. 2012).

The estimated passage times at YLJ for the two Bar-tailed Godwit subspecies were not statistically different, but L. l. baueri arrived on average on 29 March, 13 days ahead of L. l. menzbieri (11 April), which arrived at a similar time to Great Knots (7 April). The differences in arrival date between the two godwit subspecies were within the differences in departure date in Australia (10-14 days) (Wilson et al. 2007) and the first records of L. l. baueri at YLJ (II March 2011, 12 March 2012) matched the earliest departure known from New Zealand (4 March 2012, J. R. Conklin and P. F. Battley unpubl. data; the flight time to China is approximately seven days, Battley et al. 2012). L. l. baueri also departed YLJ earlier than L. l. menzbieri and Great Knots (early May versus mid-May). Late-arriving L. l. menzbieri and Great Knots have less time to refuel given their narrow departure windows. This similarity in phenology between Great Knots and menzbieri godwits is unsurprising, given that both have similar non-breeding and breeding ranges. 


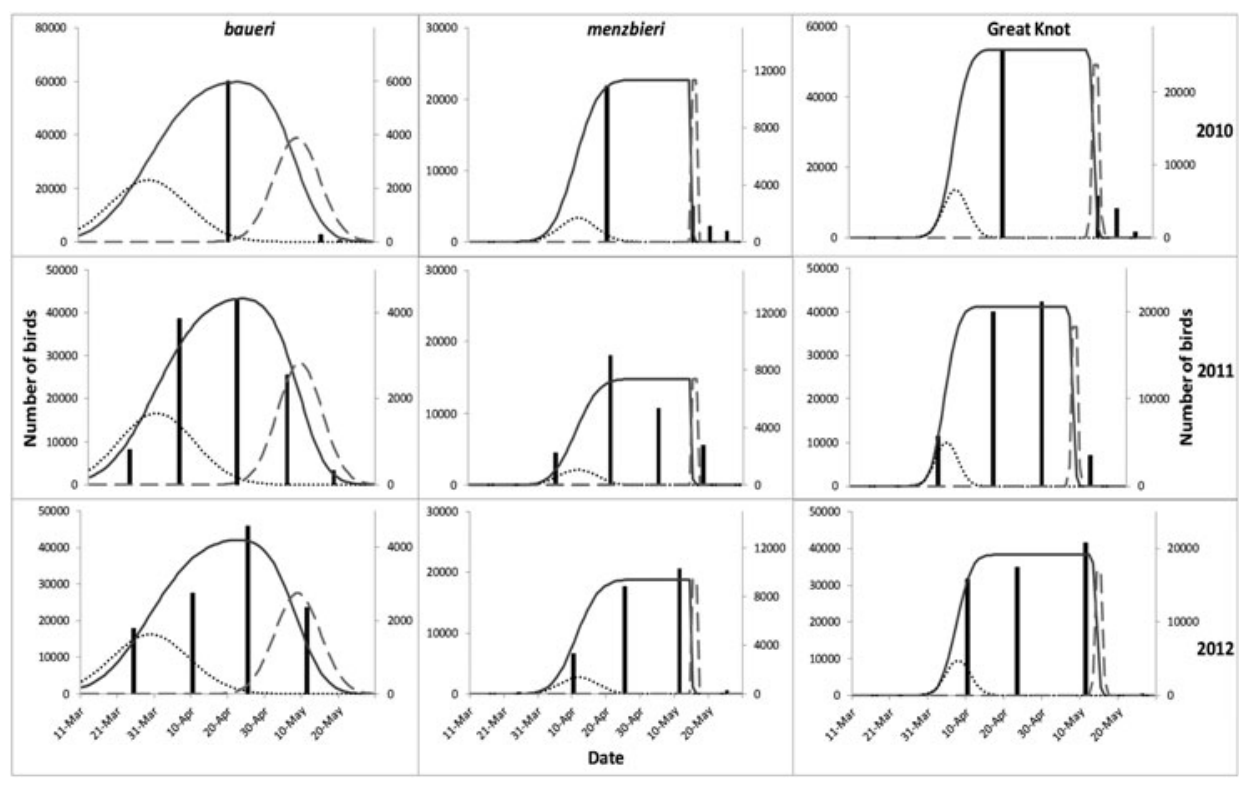

Figure 3. Total numbers of Bar-tailed Godwits and Great Knots staging at the Chinese side of Yalu Jiang coastal wetland during northward migration from 2010 to 2012. Bars represent observed count data from periodic synchronised censuses, solid lines the modelled estimate based on count data from periodic synchronised censuses (both were plotted against the left y-axis). Dotted lines represent the number of birds estimated to arrive and dashed lines the number of birds estimated to depart (both plotted against the right y-axis), thus areas under the dotted and dashed lines are equal and both represent the total number of birds.

Their narrower departure windows than L. l. baueri probably relate to their smaller latitudinal breeding range, and hence less geographical variation in thaw dates than in Alaska (Green et al. 2002, Wilson et al. 2007, Bamford et al. 2008, Conklin et al. 2010). The same reasoning could be applied to the relatively large numbers of L. l. baueri remaining at YLJ until the middle of May. These probably breed further north in Alaska than earlier-departing L. l. baueri (Conklin et al. 2010).

\section{Assessment of counting and modelling approaches}

The modelling results based on periodic synchronised census data more realistically described the migration phenology of the study species than those based on regular partial counts, at least for godwits. In fact, the estimated departure dates for Bar-tailed Godwits based on regular partial counts were too early (late April) and in the wrong order (L. l. menzbieri ahead of L. l. baueri) compared to published results (Battley et al. 2012). These suggest that regular partial counts did not provide reliable estimates. Such a result is surprising because the three main pre-roosts were counted on a 4-day rotation during regular partial counts while periodic synchronised censuses were conducted only every two weeks. Nonetheless, regular partial counts may yield high variances because the countable number of birds could be affected by different tidal levels that affect local roosting patterns or within-season changes in feeding and roost site choice as local food resources deplete (Rogers 2005). In contrast, the phenology and numbers of Great Knots estimated by the partial counts dataset were similar to those estimated with the synchronised census dataset. This reflects the fact that Great Knots were concentrated more in areas covered during the partial counts - on average $75 \%$ of the Great Knots counted during the synchronised censuses 
Table 3. Estimated total numbers of Bar-tailed Godwits and Great Knots at the Chinese side of Yalu Jiang coastal wetland during northward migration, 2010-2012. Numbers are modelled from periodic synchronised censuses, using passage time parameters from either synchronised census or regular partial count data. Values are presented as estimates \pm asymptotic standard error.

\begin{tabular}{lllll}
\hline Year & Data type & L. l. baueri godwit & L. l. menzbieri godwit & Great Knot \\
\hline \multirow{2}{2}{ O10 } & Estimate: synchronised & $60,818 \pm 6,539$ & $22,722 \pm 4,732$ & $53,409 \pm 3,832$ \\
& Estimate: partial & $82,425 \pm 13,452$ & $38,394 \pm 8,727$ & $39,574 \pm 5,491$ \\
& Actual: peak count & 60,319 & 21,828 & 53,409 \\
\multirow{2}{*}{011} & Estimate: synchronised & $44,090 \pm 6,550$ & $14,775 \pm 2,197$ & $41,198 \pm 2,709$ \\
& Estimate: partial & $50,246 \pm 8,094$ & $32,736 \pm 7,749$ & $39,655 \pm 4,644$ \\
\multirow{2}{*}{2012} & Actual: peak count & 43,011 & 18,087 & 42,357 \\
& Estimate: synchronised & $42,814 \pm 5,895$ & $18,816 \pm 2,079$ & $38,320 \pm 2,709$ \\
& Estimate: partial & $45,070 \pm 8,367$ & $32,533 \pm 7,640$ & $37,187 \pm 4,139$ \\
& Actual: peak count & 45,839 & 20,577 & 41,635 \\
\cline { 2 - 4 } & $\mathrm{R}^{2}:$ synchronised & 0.97 & 0.96 & 0.99 \\
& $\mathrm{R}^{2}:$ partial & 0.89 & 0.81 & 0.94 \\
\hline
\end{tabular}

were present at partial count sites, whereas only $43 \%$ of the godwits were. Overall, less frequent, but thorough periodic synchronised censuses at high tide during spring tides seem to be a more effective way to collect data for modelling shorebird populations at staging sites when survey resources are limited. The stable peak found in L. l. menzbieri (from late April to early May) and Great Knots (from mid April to early May) indicated that their transiting numbers can be reliably counted over the peak period (Figure SI). Periodic synchronised censuses should be completed within the shortest period of time if they cannot be done on the same day, to minimise doublecounting as birds may move between surveyed sites during the census period. This might have yielded the significantly higher estimates for L. l. baueri and Great Knots in 2010 (one of the censuses spanned over 1o days) compared to other years, when the spans did not exceed 4 days.

The similar estimated passage times based on periodic synchronised census data to tracking records suggested that both periodic synchronised census and tracking methods with limited sample sizes provide reasonably good estimates for passage times. The estimated numbers of birds staging were similar to the peak counts in most cases, indicating that a single thorough survey during the peak season could still be used to represent the total number of L. l. menzbieri and Great Knots staging at YLJ if resources are limited. However, there were two occasions when the $95 \%$ range of estimated number of birds was lower than the peak counts (L. l. menzbieri 2011, Great Knot 2012). Such inconsistency may arise due to statistical error in the count totals.

The accuracy of Thompson's modelling approach relies on the assumption that arrival and departure times are normally distributed, which may vary depending on species, site and time. This assumption may be violated in situations where there is substantial variation between the passage times of individuals. This is more likely to occur during southward migration when populations may comprise different age-groups or use the same site differently (e.g. staging or moulting) (Newton 2008, Choi et al. 2009). However, this modelling approach generated accurate passage time estimates in this study, which we could independently confirm from data from tracking studies (Battley et al. 2012, Ma et al. 2013). We believe that its application for estimating total numbers would be more useful at stopover (rather than staging) sites, where there is a larger overlap between arriving and departing birds (e.g. L. l. baueri in this study) and the peak counts are likely to underestimate the total number of birds transiting (e.g. Chongming Dongtan, Ma et al. 2013).

The use of photographs to estimate subspecies proportions in Bar-tailed Godwits could usefully be applied in similar studies where different subspecies, sexes or ages of birds are identifiable by plumage and occur at the same study site. It is important to check whether different groups of birds in the study area have different distributions. Given that more than $70 \%$ of the Bar-tailed Godwits occur in the eastern half of the reserve (Riegen et al. 2014) and large numbers of photographs were used in our study, the potential impacts of uneven distribution between godwit subspecies are minimised. 


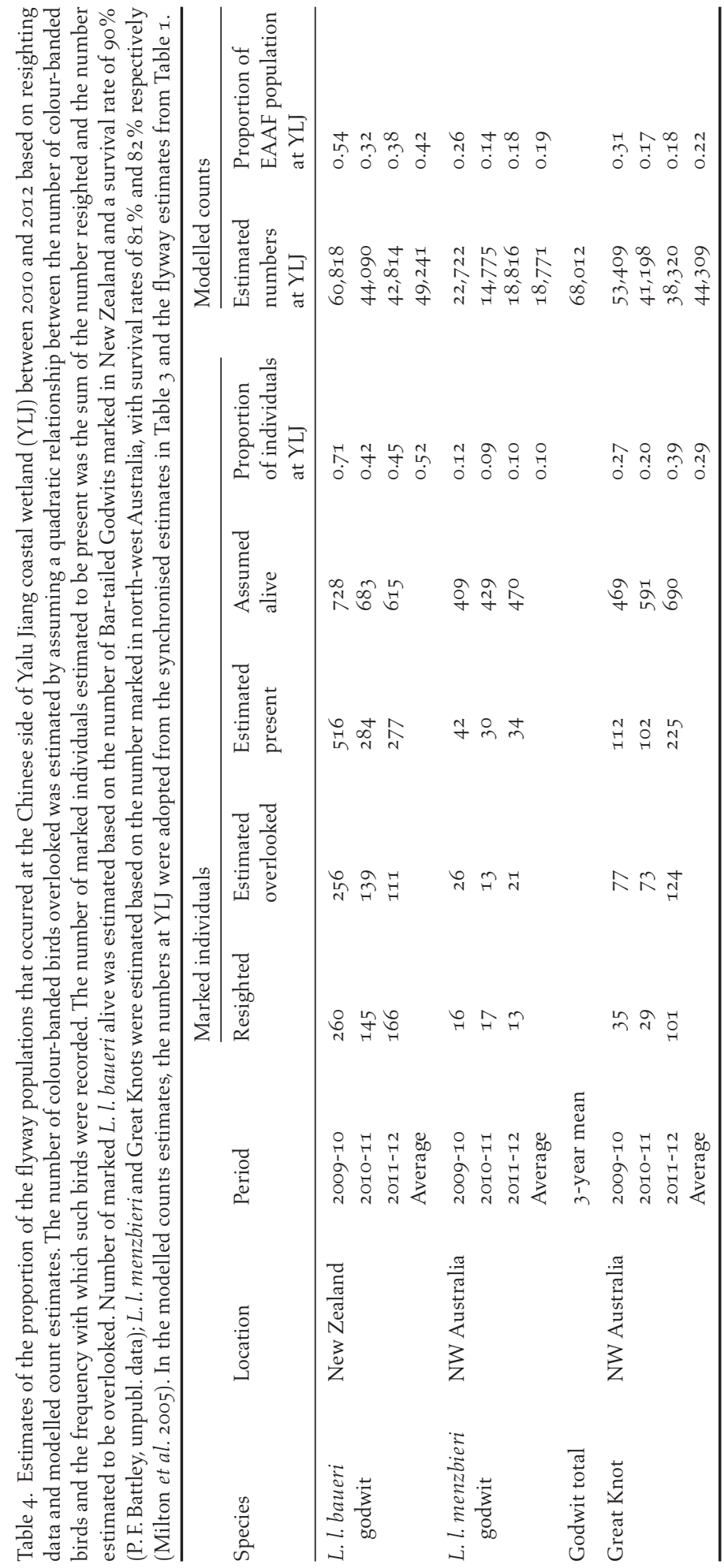




\section{Importance of Yalu Jiang coastal wetland}

Our results reinforce the claim that YLJ is the most important northward migration staging site for Bar-tailed Godwits and indicate that the study area has become the most important known northward migration staging site for Great Knots along the EAAF (Barter 2002, Bamford et al. 2008, Moores 2012). According to the results of modelling count data, YLJ supports an average of at least $42 \%$ of northward-migrating L. l. baueri, $19 \%$ of L. l. menzbieri, and $22 \%$ of Great Knots along the EAAF. An independent check on the importance of YLJ based on colour-band data indicated that an average of $52 \%$ of New Zealand colour-banded L. l. baueri, 10\% of north-west Australia colour-banded L. l. menzbieri and $29 \%$ of north-west Australia colour-banded Great Knots staged at YLJ. The differences between these estimates and the ones based on modelling count data could arise because of different scanning effort and different populations may have different tendencies to move in and out of the our main scanning area in different years, subject to food availability. The low proportion of colour-banded L. l. menzbieri resighted could arise if the population at YLJ mainly comes from wintering areas further east of north-west Australia where the banding work has been conducted. Nonetheless, the resighting data are consistent with the modelling data in suggesting that YLJ supports a large proportion of L. l. baueri and Great Knot migrant populations along the EAAF.

Using the passage dates estimated and the peak count data from this study, a comparison with historical peak count data indicated an 18\% decline in Great Knots (compared to 1999) and a 13\% decrease in Bar-tailed Godwit (compared to 2004) (Barter and Riegen 2004) (Table 5). More recently, the number of Bar-tailed Godwits counted at YLJ during northward migration declined rapidly from 99,611 in 2009 to 63,479 in 2012 (36.3\% decline). This decline coincided with a port development project at the eastern end of the reserve boundary (Figure 1 , east of site 1 ), which started in June 2008, was half-completed in January 2011, and almost completed in February 2013, dividing the main foraging tidal flats of Bar-tailed Godwits at YLJ (as indicated by satellitetracking, P. F. Battley unpubl. data) into two. It is difficult to determine whether the decline implies a drop in the total population or merely a redistribution of roosting birds. Despite the decline in numbers compared to historical counts, YLJ has become the most important known staging site for Great Knots during northward migration due to the destruction of the two most important staging sites, namely the Dongjin and Mangyeung Estuaries in South Korea (Bamford et al. 2008, Birds Korea 2010, Moores 2012).

\section{Conservation implications}

It is clear that YLJ plays an important role for Bar-tailed Godwits and Great Knots during northward migration. Thirteen other species are reported to occur in internationally important numbers during northward migration at the study area (Bamford et al. 2008). Additional evidence for the importance of this site will become available when latest count data from both northward and southward migration for species such as Nordmann's Greenshanks Tringa guttifer ('Endangered'), Kentish Plovers Charadrius alexandrinus and Spotted Redshanks Tringa erythropus are analysed (IUCN 2012). It is strongly encouraged that the reserve seeks Ramsar recognition to further protect the area from reclamation such as the recent loss of $34 \mathrm{~km}^{2}$ of tidal flat through port development at the east of the reserve boundary. The long-term impact of such development should not be overlooked. Previous reports of sediments at Yalu Jiang estuary being transported westwards under the influence of tides and waves (Wang and Aubrey 1987) imply that the new 1o-km seawall extending towards the sea might not merely mean an immediate loss of intertidal flat but a further loss of intertidal flat in the study area due to the loss of sediment supply from the river (Figure 1). On the other hand, our results indicate that the Ashpond, a high tide roost located further east of the reserve boundary, holds an average of $20 \%$ of the Bar-tailed Godwits counted during our periodic synchronised censuses. The existence of important roosting habitat outside the reserve boundary, and activities outside the reserve that may have damaging effects on the 


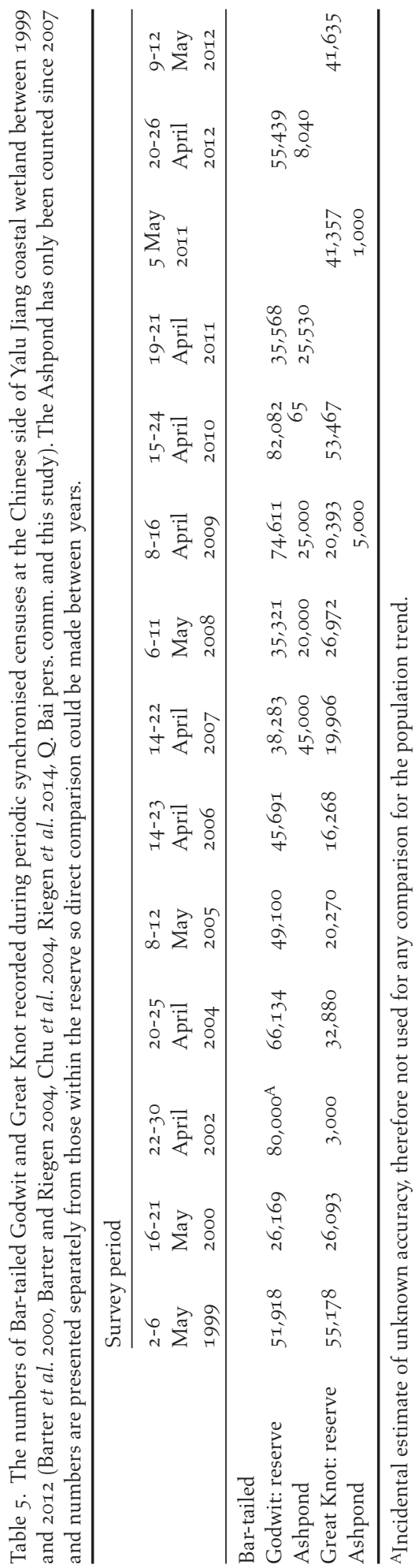


reserve, indicate that the status of surrounding areas should be taken into consideration when making management decisions.

Finally, with the advantage of a good understanding of the study area and independent tracking dataset to examine the modelling results, we have shown that a combination of periodic synchronised censuses and Thompson's modelling approach can provide reliable estimates of passage times and numbers of transiting birds at staging sites. Such an approach should be applied elsewhere to test for its validity. This is particularly relevant to the growing amount of data available along the east China coast, where shorebirds from 13 areas have been surveyed monthly since 2005 (China Coastal Waterbird Census Group 2009, 2011).

\section{Acknowledgements}

CYC was supported by the New Zealand Government under the New Zealand International Doctoral Research Scholarships programme. This study was financially supported by the National Natural Science Foundation of China (31071939). We are indebted to Q.-Q. Bai, D. Melville, J. Melville, Y. Chen, H.-B. Peng, C.-Y. Chiang and S.-H. Hsu for field assistance. We thank the Dandong Yalu Jiang Estuary Wetland National Nature Reserve for facilitating our fieldwork and contributing to the periodic synchronised census. We are grateful to the Miranda Naturalists' Trust, especially A.C. Riegen, for sharing their knowledge and experiences of shorebirds at the study site. We appreciate The Australasian Wader Studies Group, C. J. Hassell, D. I. Rogers, the Ornithological Society of New Zealand, Q.-Q. Bai for allowing us to examine their count data, C. J. Hassell of the Global Flyway Network and R. Schuckard for allowing us to examine their colour-banding data, and J. R. Conklin, T. L. Tibbitts, R. E. Gill, Jr., and the US Geological Survey for allowing us to examine the satellite tracking and geolocator data. We would also like to thank P. Atkinson and two anonymous referees for their comments on earlier versions of the manuscript.

\section{References}

Amano, T., Szekely, T., Koyama, K., Amano, H. and Sutherland, W. J. (2010) A framework for monitoring the status of populations: An example from wader populations in the East Asian-Australasian flyway. Biol. Conserv. 143: 2238-2247.

An, S. Q., Li, H. B., Guan, B. H., Zhou, C. F., Wang, Z. S., Deng, Z. F., Zhi, Y. B., Liu, Y. H., $\mathrm{Xu}$, C., Fang, S. B., Jiang, J. H. and Li, H. L. (2007) China's natural wetlands: Past problems, current status, and future challenges. AMBIO 36: 335-342.

Bamford, M., Watkins, D., Bancroft, W., Tischler, G. and Wahl, J. (2008) Migratory shorebirds of the East Asian-Australasian Flyway; population estimates and internationally important sites. Canberra, Australia: Wetlands International - Oceania.

Barter, M. (2002) Shorebirds of the Yellow Sea: importance, threats and conservation status Canberra, Australia: Wetlands International Global Series 9. International Wader Studies 12.
Barter, M. and Riegen, A. (2004) Northward shorebird migration through Yalu Jiang National Nature Reserve. Stilt 46: 9-14.

Barter, M. A., Wilson, J. R., Li, Z. W., Dong, Z. G., Cao, Y. G. and Jiang, L. S. (2000) Yalu Jiang National Nature Reserve, North-eastern China - A newly discovered internationally important Yellow Sea site for northward migrating shorebirds. Stilt 37: 13-20.

Battley, P. F. (2006) Consistent annual schedules in a migratory shorebird. Biol. Lett. 2 : 517-520.

Battley, P. F., Warnock, N., Tibbitts, T. L., Gill, R. E., Piersma, T., Hassell, C. J., Douglas, D. C., Mulcahy, D. M., Gartrell, B. D., Schuckard, R., Melville, D. S. and Riegen, A. C. (2012) Contrasting extreme long-distance migration patterns in bar-tailed godwits Limosa lapponica. J. Avian Biol. 43: 21-32.

BirdLife International (2009) Directory of Important Bird Areas in China (mainland): Key sites for conservation. Cambridge, UK: BirdLife International. 
Birds Korea (2010) The Birds Korea Blueprint 2010 for the conservation of the avian biodiversity of the South Korean part of the Yellow Sea. Seoul: Birds Korea, October 2010.

China Coastal Waterbird Census Group (2009) China coastal waterbird census report (Sep. 2005-Dec. 2007). Hong Kong: Hong Kong Birdwatching Society Limited.

China Coastal Waterbird Census Group (2011) China coastal waterbird census report (Jan. 2008-Dec. 2009). Hong Kong: Hong Kong Birdwatching Society Limited.

Choi, C. Y., Gan, X. J., Hua, N., Wang, Y. and $\mathrm{Ma}, \mathrm{Z}$. J. (2014) The habitat use and home range analysis of Dunlin (Calidris alpina) in Chongming Dongtan, China and their conservation implications. Wetlands 34: 255-266.

Choi, C. Y., Gan, X. J., Ma, Q., Zhang, K. J., Chen, J. K. and Ma, Z. J. (2009) Body condition and fuel deposition patterns of calidrid sandpipers during migratory stopover. Ardea 97: 61-70.

Chu, G., Collins, P., Melville, D. and Qian, F. (2004) Report on the first Sino-Australia flagging workshop at Yalu Jiang National Nature Reserve, China, April 2002. Stilt 46: $4 \mathrm{O}-47$.

Cohen, J. B., Karpanty, S. M., Fraser, J. D., Watts, B. D. and Truitt, B. R. (2009) Residence probability and population size of Red Knots during spring stopover in the Mid-Atlantic region of the United States. J. Wildl. Manage. 73: 939-945.

Conklin, J. R. and Battley, P. F. (2011) Impacts of wind on individual migration schedules of New Zealand bar-tailed godwits. Behav. Ecol. 22: 854-861.

Conklin, J. R., Battley, P. F. and Potter, M. A. (2013) Absolute consistency: individual versus population variation in annual-cycle schedules of a long-distance migrant bird. PLOS ONE 8: e54535.

Conklin, J. R., Battley, P. F., Potter, M. A. and Fox, J. W. (2010) Breeding latitude drives individual schedules in a trans-hemispheric migrant bird. Nature Commun. 1: 67.

Efford, M. G. (2005) Migrating birds stop over longer than usually thought: Comment. Ecology 86: 3415-3418.
Engelmoer, M. and Roselaar, C. S. (1998) Geographical variation in waders. Dordecht: Kluwer Academic Publishers.

Farmer, A. and Durbian, F. (2006) Estimating shorebird numbers at migration stopover sites. Condor 108: 792-807.

Frederiksen, M., Fox, A. D., Madsen, J. and Colhoun, K. (2001) Estimating the total number of birds using a staging site. J. Wildl. Manage. 65: 282-289.

Gan, X. J., Cai, Y. T., Choi, C. Y., Ma, Z. J., Chen, J. K. and Li, B. (2009) Potential impacts of invasive smooth cordgrass Spartina alterniflora spread on bird communities at Chongming Dongtan, a Chinese wetland of international importance. Estuar. Coast. Shelf Sci. 83: 211-218.

Green, M., Piersma, T., Jukema, J., De Goeij, P., Spaans, B. and Van Gils, J. A. (2002) Radio-telemetry observations of the first $650 \mathrm{~km}$ of the migration of Bar-tailed Godwits Limosa lapponica from the Wadden Sea to the Russian Arctic. Ardea 90: 71-80.

Hua, N., Piersma, T. and Ma, Z. (2013) Threephase fuel deposition in a long-distance migrant, the Red Knot Calidris canutus piersmai, before the flight to high arctic breeding grounds. PLoS ONE 8: e62551.

IUCN (2012) IUCN Red List of Threatened Species. Version 2012.2. <www.iucnredlist. org $>$. Accessed on 30 January 2013.

Li, Z. W. D., Bloem, A., Delany, S., Martakis, G. and Quintero, J. O. (2009) Status of waterbirds in Asia - results of the Asian waterbird census: 1987-2007. Kuala Lumpur, Malaysia: Wetlands International.

Ma, Z. J., Hua, N., Peng, H. B., Choi, C. Y., Battley, P., Zhou, Q. Y., Chen, Y., Ma, Q., Jia, N., Xue, W. J., Bai, Q. Q., Wu, W., Feng, X. S. and Tang, C. D. (2013) Differentiating between stopover and staging sites: functions of the southern and northern Yellow Sea for long-distance migratory shorebirds. J. Avian Biol. 44: 504-512.

Ma, Z. J., Wang, Y., Gan, X. J., Li, B., Cai, Y. T. and Chen, J. K. (2009) Waterbird population changes in the wetlands at Chongming Dongtan in the Yangtze River estuary, China. Environ. Manage. 43: 1187-1200.

MacKinnon, J., Verkuil, Y. I. and Murray, N. (2012) IUCN situation analysis on East and Southeast Asian intertidal habitats, 
with particular reference to the Yellow Sea (including the Bohai Sea). Gland, Switzerland and Cambridge, UK: IUCN. (Occasional Paper of the IUCN Species Survival Commission No. 47).

Matechou, E., Morgan, B. J. T., Pledger, S., Collazo, J. A. and Lyons, J. E. (2013) Integrated analysis of capture-recaptureresighting data and counts of unmarked birds at stop-over sites. J. Agric. Biol. Environ. Stat. 18: 120-135.

Milton, D., Minton, C. and Gosbell, K. (2005) Are populations of migratory shorebirds in the East Asian Australasian Flyway at risk of decline? Pp. 153-157 in P. Straw, ed. Status and conservation of shorebirds in the East Asian-Australasian Flyway; Proceedings of the Australasian shorebirds conference 13-15 December 2003, Canberra, Australia. Sydney, Australia: Australasian Wader studies Group and Wetlands International.

Minton, C., Dann, P., Ewing, A., Taylor, S., Jessop, R., Anton, P. and Clemens, R. (2012) Trends of shorebirds in Corner Inlet, Victoria, 1982-2011. Stilt 61: 3-18.

Moores, N. (2012) The distribution, abundance and conservation of avian biodiversity in Yellow Sea habitats in the Republic of Korea. PhD thesis. University of Newcastle, Australia.

Moores, N., Rogers, D., Kim, R. H., Hassell, C., Gosbell, K., Kim, S. A. and Park, M. N. (2008) The 2006-2008 Saemangeum Shorebird Monitoring Program Report. Busan: Birds Korea publication.

Murray, N. J., Clemens, R. S., Phinn, S. R., Possingham, H. P. and Fuller, R. A. (2014) Tracking the rapid loss of tidal wetlands in the Yellow Sea. Front. Ecol. Environ. 12: 267-272.

Newton, I. (2008) The migration ecology of birds. Oxford, UK: Academic Press.

Piersma, T., van Gils, J. and Wiersma, P. (1996) Family Scolopacidae (sandpipers, snipes and phalaropes). Pp. 444-533 in J. Del Hoyo, A. Elliott and J. Sargatal, eds. Handbook of the birds of the world. Barcelona: Lynx Edicions.

Pradel, R., Schaub, M., Jenni, L. and Lebreton, J. D. (2005) Migrating birds stop over longer than usually thought: Reply. Ecology 86: 3418-3419.
Ramsar (2012) The list of wetlands of international importance. <www.ramsar.org/pdf/ sitelist.pdf $>$. Accessed on 19 November 2012.

Riegen, A. C., Vaughan, G. R. and Rogers, K. D. (2014) Yalu Jiang Estuary shorebird survey report 1999-2010. Yalu Jiang Estuary Wetland National Nature Reserve, China and Miranda Naturalists' Trust, New Zealand.

Rogers, D. (2005) Distribution of shorebirds along Eighty-Mile Beach. Pp. 163-206 in G. Pearson, T. Piersma, R. Hickey and M. Lavaleye, eds. The Long mud: Benthos and shorebirds of the foreshore of EightyMile Beach, Western Australia. Texel, The Netherlands: NIOZ.

Rogers, D. I., Hassell, C. J., Boyle, A., Gosbell, K., Minton, C., Rogers, K. G. and Clarke, R. T. (2011) Shorebirds of the Kimberley Coast Populations, key sites, trends and threats. J. Roy. Soc. Western Australia 94: 377-391. Rogers, D. I., Yang, H. Y., Hassell, C. J., Boyle, A. N., Rogers, K. G., Chen, B., Zhang, Z. W. and Piersma, T. (2010) Red Knots (Calidris canutus piersmai and C. c. rogersi) depend on a small threatened staging area in Bohai Bay, China. Emu 110: 307-315.

Stroud, D. A., Baker, A., Blanco, D. E., Davidson, N. C., Delany, S., Ganter, B., Gill, R., González, P., Haanstra, L., Morrison, R. I. G., Piersma, T., Scott, D. A., Thorup, O., West, R., Wilson, J., and Zöckler, C. (on behalf of the International Wader Study Group) (2006) The conservation and population status of the world's waders at the turn of the millennium. Pp. 643-648 in G. C. Boere, C. A. Galbraith and D. A. Stroud, eds. Waterbirds around the world. Edinburgh, UK: The Stationery Office.

Systat Software Inc (2007) Systat 12.0. Richmond, CA: Systat Software Inc.

Thompson, J. J. (1993) Modelling the local abundance of shorebirds staging on migration. Theor. Popul Biol. 44: 299-315.

Tomkovich, P. S. (2010) Assessment of the Anadyr lowland subspecies of Bar-tailed Godwit Limosa lapponica anadyrensis. Bull. Brit. Ornithol. Club 130: 88-95.

UNDP/GEF (2007) The Yellow Sea: Analysis of environmental status and trends, Volume 1, Part I: National reports - China. Ansan, Republic of Korea UNDP/GEF Yellow Sea Project. 
Wang, Y. and Aubrey, D. G. (1987) The characteristics of the China coastline. Cont. Shelf Res. 7: 329-349.

Warnock, N. (2010) Stopping vs. staging: the difference between a hop and a jump. J. Avian Biol. 41: 621-626.

Wilson, H. B., Kendall, B. E., Fuller, R. A., Milton, D. A. and Possingham, H. P. (2011) Analyzing variability and the rate of decline of migratory shorebirds in Moreton Bay, Australia. Conserv Biol 25: $758-766$.

Wilson, J. R., Nebel, S. and Minton, C. D. T. (2007) Migration ecology and morphometrics of two Bar-tailed Godwit populations in Australia. Emu 107: 262-274.
Wetlands International (2013) Waterbird population estimates. <wpe.wetlands.org> Accessed on 11 January 2013.

Yan, M. F. ed. (2008) Scientific survey of Dandong Yalu Jiang Wetland National Nature Reserve. Shenyang, China: Liaoning University Press.

Yang, H. Y., Chen, B., Barter, M., Piersma, T., Zhou, C. F., Li, F. S. and Zhang, Z. W. (2011) Impacts of tidal land reclamation in Bohai Bay, China: ongoing losses of critical Yellow Sea waterbird staging and wintering sites. Bird Conserv. Internatn. 21: 241-259.

Zar, J. H. (1999) Biostatistical analysis. Fourth edition. Upper Saddle River, New Jersey: Prentice Hall.

\section{CHI-YEUNG CHOI*, PHIL F. BATTLEY, MURRAY A. POTTER}

Ecology Group, Institute of Agriculture and Environment, PN 624, Massey University, Private Bag 11-222, Palmerston North, 4442, New Zealand.

\section{KEN G. ROGERS}

340 Ninks Road, St Andrews, Vic. 3761, Australia.

\section{ZHIJUN MA}

Ministry of Education Key Laboratory for Biodiversity Science and Ecological Engineering, Institute of Biodiversity Science, Fudan University, Shanghai, 200433, P. R. China.

*Author for correspondence; e-mail:choimo@yahoo.com

Received 25 May 2013; revision accepted 13 November 2013; Published online 14 August 2014 